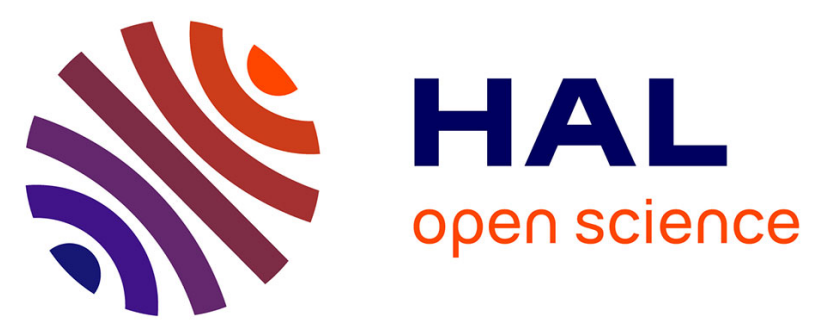

\title{
A new approach to predict the visual appearance of rose bush from image analysis of 3D videos
}

Morgan Garbez, M. Sigogne, Yann Chéné, Nicolas Dones, Etienne Belin, Gilles Hunault, D. Relion, Ronan Symoneaux, D. Rousseau, Gilles Galopin

\section{- To cite this version:}

Morgan Garbez, M. Sigogne, Yann Chéné, Nicolas Dones, Etienne Belin, et al.. A new approach to predict the visual appearance of rose bush from image analysis of 3D videos. Eur. J. Hortic. Sci, 2020, 85, pp.182 - 190. 10.17660/eJHS.2020/85.3.6 . hal-02892198

\section{HAL Id: hal-02892198}

\section{https://institut-agro-rennes-angers.hal.science/hal-02892198}

Submitted on 7 Jul 2020

HAL is a multi-disciplinary open access archive for the deposit and dissemination of scientific research documents, whether they are published or not. The documents may come from teaching and research institutions in France or abroad, or from public or private research centers.
L'archive ouverte pluridisciplinaire $\mathbf{H A L}$, est destinée au dépôt et à la diffusion de documents scientifiques de niveau recherche, publiés ou non, émanant des établissements d'enseignement et de recherche français ou étrangers, des laboratoires publics ou privés. 


\title{
A new approach to predict the visual appearance of rose bush from image analysis of 3D videos
}

\author{
M. Garbez ${ }^{1,2}$, É. Belin ${ }^{3}$, Y. Chéné ${ }^{3}$, N. Donès ${ }^{4}$, G. Hunault ${ }^{5}$, D. Relion ${ }^{1}$, M. Sigogne ${ }^{1}$, R. Symoneaux ${ }^{6}$, \\ D. Rousseau ${ }^{7}$ and G. Galopin ${ }^{1}$ \\ ${ }^{1}$ IRHS, INRAE, Institut Agro, Université d'Angers, SFR 4207 QuaSaV, 49071, Beaucouzé, France \\ 2 Pépinières Desmartis, Bergerac, France \\ ${ }^{3}$ Université d'Angers, Laboratoire Angevin de Recherche en Ingénierie des Systèmes (LARIS), Angers, France \\ ${ }^{4}$ PIAF, INRAE, UCA, Clermont-Ferrand, France \\ ${ }^{5}$ Université d’Angers, Laboratoire Hémodynamique, Interaction, Fibrose, et Invasivité Tumorale Hépatique (HIFIH), Angers, \\ France \\ ${ }^{6}$ Unité de Recherche GRAPPE, Université Bretagne Loire, Ecole Supérieure d'Agricultures (ESA), INRA, Angers, France \\ ${ }^{7}$ Université de Lyon, Centre de Recherche en Acquisition et Traitement de l'Image pour la Santé (CREATIS), Villeurbanne, \\ France
}

\section{Summary}

Sensory methods applied to ornamental plants enable studying more objectively plant visual quality key drivers of consumer preferences. However, management upkeep of a trained panel for sensory profile is time-consuming, not flexible and represents non-negligible costs. The present paper achieves the proof of the concept about using morphometrical descriptors integrating 2D image features from rotating virtual rose bush videos to predict their visual appearance according to different sensory attributes. Using real plants cultivated under a shading gradient and imaged in rotation during three development stages, acceptable prediction error of the sensory attributes ranging from 6.2 to $19.8 \%$ (normalized RMSEP) were obtained with simple ordinary least squares (OLS) regression models and linearization. The most accurate model obtained was for the flower quantity perception. Finally, a secondary analysis highlighted in most of the studied traits a significant influence of defoliation, stressing therefore the impact of the leaves on plant architecture, and thus on the visual appearance.

\section{Keywords}

image analysis, linear regression, Rosa hybrida, sensory profile, video, woody ornamental plant

\section{Introduction}

To objectivize ornamental plant visual quality studies, visual assessments from human perception following non-hedonic sensory analysis methods represent a powerful and pragmatic way to compare the plants. Developed on rose bush plants, panelists, thanks to training, seem quite adaptable to various supports for plant presentation, at different development stages, from different genotypes or cultural practices (Boumaza et al., 2009, 2010; Huché-Thélier et al., 2011; Garbez et al., 2015, 2016). However, upkeeping a perennial trained panel, limited by fatigue and individual performance, implies also a non-negligible financial cost.

Especially addressed in Garbez et al. (2018), the visual appearance of a rose bush is intimately linked to its archi-

\section{Significance of this study}

What is already known on this subject?

- Visual quality of ornamental plants is a key parameter playing a major role in the purchase triggering for consumers. Visual quality can be assessed by a panel of consumers from 2D views by considering homogeneous plants in their rotation.

What are the new findings?

- Use of morphometric descriptors evaluated in 3D by rotation on video by image analysis to predict sensory attribute scores for ornamental plants. This method, developed from virtual roses (Garbez et al., 2016), is validated for real plants with high phenotypic variability.

What is the expected impact on horticulture?

- Within ornamental horticulture context, visual quality of plants is an important criterion for customers. The realization of a sensory evaluation of the aesthetic value is important. Its prediction by morphometric attributes allows it to be automatized and generalized easily and quickly. It's future tool to help innovation in ornamental horticulture.

tecture (Huché-Thélier et al., 2011; Santagostini et al., 2014; Garbez et al., 2015). Governed by environmental and genotypic influences, architecture is resulting from the different botanical entities, with their proper morphologic and geometric characteristics, located in a 3D space and arranged topologically either by succession or branching relations (Godin, 2000; Barthélémy and Caraglio, 2007; Li-Marchetti et al., 2015). To study visual appearance in relation with the plasticity of plant architecture in routine without long-term panel managements, growers, breeders and scientists, need therefore faster and more objective methods providing consistent measurements in order to set automated characterization processes.

Santagostini et al. (2014) proposed a first method using images of single facet of different rose bush cultivars. They demonstrated that the "area ratio of the flowers surface over complete plant surface" was highly correlated with the 
number of hand-counted flowers and 'floribundity' sensory attributes. For other attributes assessed on 20 rotating virtual rose bush videos representing approximately fivemonths-old plants after complete petal abscission, Garbez et al. (2015) obtained good predictive models with ordinary least squares (OLS) regression. The OLS models used very few morphometric descriptors (MD) obtained from descriptive statistics summarizing values of image features extracted from 45 side views (facets) all around the plants, i.e., interspaced by $8^{\circ}$ rotation interval.

The main goal of this paper is to propose an objective and automatic method to characterize 3D visual appearance of real rose bush. The genericity of the approach is presented with an application domain extension generated using videos presenting the plants cultivated under different shading environments at three stages of development: the first and third times with leaves and flowers, interspaced by a second stage during rest phase presenting plants without leaves and flowers.

With this main goal, two other complementary objectives are addressed: (i) the reduction of the number of images for the morphometric descriptor computation, considered for modeling the sensory attribute related to the flower quantity perception; (ii) the impact of plant defoliation before architecture digitizing. Indeed, during the rest period plants can be marketed without leaves and the visual appearance is important.

\section{Material and methods}

\section{Plant material and growth conditions}

As fully described in Garbez et al. (2018), plants used were 'Radrazz' Knock Out ${ }^{\circledR}$ potted rose bushes (Rosa hybrida L.). Plant material was obtained from single node cuttings, then after rooting and first flowering, three plant batches were formed to be outdoor cultivated in container and under contrasted shading conditions: natural condition (a control without shading screen denoted 0\%); under a tunnel covered with a 55\%; or 75\% shading screen. During the winter (December to February), plants were moved to an unheated polyethylene tunnel to prevent any frost damages on roots and future young shoots.

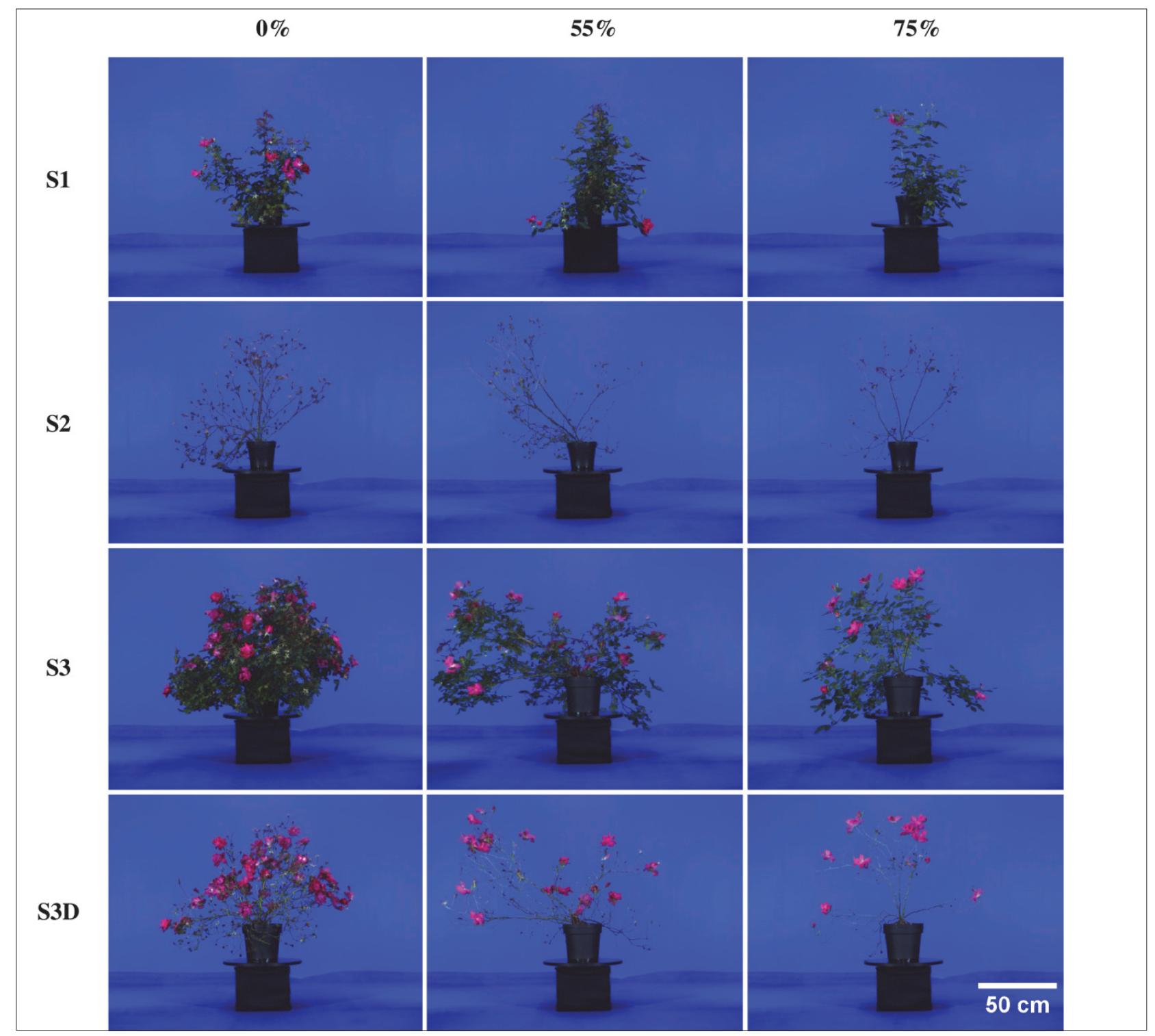

FIGURE 1. Panel of cropped and reduced size images of three rose bushes from the different shading environments (from the left to the right: 0,55 , and $75 \%$ of shading) over the three acquisition stages (from the top to the bottom: S1, S2, S3), then manually defoliated at the third stage (S3D). 


\section{Plant acquisitions and sensory profile}

As fully described in Garbez et al. (2018), multiple front views of the plants were imaged using a motorized turntable coupled with a CCD camera. This image acquisition made it possible to obtain image sequences for image analysis and rotating plant videos for sensory profile.

During a year and a half, plants were imaged at three stage of development: first stage (S1) was in early summer at 5 months of age, plants with flowers and leaves; second stage (S2) in late autumn-winter, during rest phase, at 12 months of age, plants without leafy or flowering axes; and last stage (S3) before summer, at 15 months of age in full flowering. For studying the impact of removing leaves on plants, plants of last stage (S3) were defoliated. Approximately half of them were subjected to image acquisition a second time immediately after defoliation to constitute a separate sample denoted S3D (Figure 1).

Image stacks of the plants were then used to edit videos presenting them in rotation. Thereafter, a panel of 20 trained subjects (panelists) was solicited for establishing the visual characterization of the plants over the 198 different videos: 171 videos (19 plants $\times 3$ shading environments $\times 3$ stages) obtained in natural condition, i.e., in flowering during plant growth or without leaf and flower during the plant rest phase and 27 other videos ( 9 plants $\times 3$ shading environments) manually defoliated after the third acquisition stage. Plant videos were anonymized, and thus scored independently of the acquisition time and the shading condition of the plants. The sensory attributes considered were related to plant dimensions, shape, branching, leaves, and flowering. In the present study, the attributes beforehand highlighted as not enough consensual (Garbez et al., 2018) were not considered. The studied variables were the attribute average scores of the panelists per product (plant video), which were considered as the response variables to be predicted.

\section{Image analysis and computation of the morphometric descriptors}

Rose bushes front view image sequences were obtained with a specifically devised RGB imaging system detailed in Garbez et al. (2018). Each rose bush in its black pot was positioned on a black motorized turntable located in room with a blue background after image capture of the scene with a plant-free pot. Then, front view images of the plant were acquired every $1^{\circ}$ of the turntable, thus for a total of 360 plant facets.

The method to process such images is based on a threestep algorithm developed using MatLab environment (The MathWorks ${ }^{\circledR}$, Inc.) which computes a binary mask of the branches and the flowers of the plant from a RGB image. Various thresholds are used in this algorithm. Each value of threshold is automatically calculated by the method of Otsu

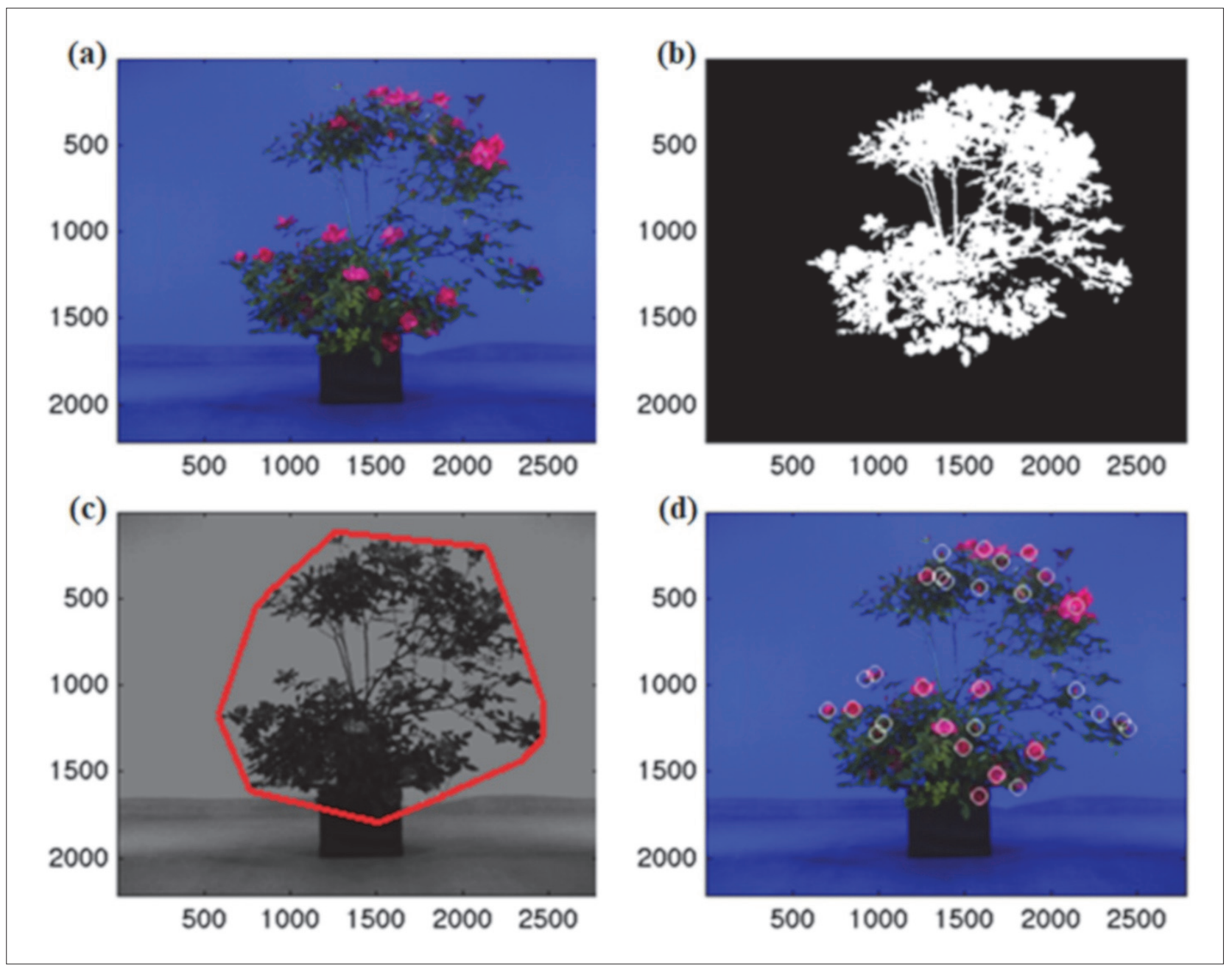

FIGURE 2. Illustration for plant image acquisition and processing (units in px): (a) an image in reduced size of a rose bush grown under a 55\% shading net at the third acquisition stage (S3); (b) corresponding plant binarized image; (c) convex hull projection (in red); (d) location and counting flowering elements. 
(1979) so that it provides some genericity to the algorithm detailed below. (i) First step aims to obtain a unique bounding box of the rose bush with its pot for the 360 poses. This consists in evaluating the bounding box of the binarized z-projection of 8 poses taken every $45^{\circ}$. The binarization of image is obtained with a simple thresholding. This bounding box is then applied on the 360 images of the plant and the image without plant. Such a bounding box both reduces the spatial size of images to be processed and the nonhomogeneity of the borders of background. (ii) Second step evaluates the position of the pot from the image acquired without plant. (iii) Third step is included in a loop for the processing of the 360 images. Each image is decomposed into two regions: a large region where the background is a blue background and a smaller region corresponding to what is in front of the black pot and the turntable. In the region with the blue background, segmentation by thresholding on the blue channel of original RGB image separates the branches (but not robustly the flowers) of the plant from the background, providing a binary mask for this first region. For the region with the pot and turntable, the algorithm computes a changing of color space from RGB to HSV where the channel "Hue" is selected because branches in front of the pot and turntable have a higher hue level than the pot and the turntable. This is followed by a thresholding segmentation and a non-linear filtering on binary image by succession of morphological operations such as erosion/ dilation to eliminate spurious isolated pixels remaining. This provides a binary mask for this second region. The binary mask of all branches is then rebuilt by combining the binary masks obtained for the two regions. For the detection of flowers, the RGB image is transformed into YIQ image. The intensity channel is selected since it presents the best contrast among the tested color space (RGB, YIQ, and HSV) between the flowers and the rest of the image. Segmentation by thresholding is applied to this channel to obtain a binary mask of the flowers. The reconstruction of the complete binary mask of the plants: plant binarized images (PBI) is the addition of the binary mask of the branches and the binary mask of the flowers. With such a binary mask, the algorithm both computes a binary mask of the plants with filled holes into the branches: plant filled images (PFI) and a binary mask of the convex hull of the plants: plant convex hull images (PCI) (Figure 2).

From there, image features were then extracted to implement various morphometric descriptors (MD) as introduced by Garbez et al. (2016), i.e., using descriptive statistics of image features along plant rotation considering PBI, PCI and PFI, some based on sub-regions sampling defined with symmetry axes, and then for flower masks. The plant base was always the lowest point for virtual rose bushes (presented without pot). With real ones it has to be defined as the top of pot center; however axes may still be under this point. Thus features previously proposed were adapted and completed with a dissociation made for this aspect. For the flower mask, features considered here were the number of isolated groups of pixels assigned to flowers; the average, quantiles, the standard deviation and the cumulated area of their surface. As proposed by Santagostini et al. (2014), the area ratio of the flowers' surface to the plant surface was also extracted, and then, as for the features obtained from the complete plant masks, the corresponding MD variables were computed with descriptive statistics of the measurements along plant rotation.

\section{Statistical analysis}

According to two separate investigations, data management and statistical analyzes were conducted under the $\mathrm{R}$ environment (R Development Core Team, 2015) with additional functions from additional packages mentioned thereafter.

The first investigation, conducted using the caret package (Kuhn, 2008, 2016), concerned the main objective of the present paper: testing the predictive modeling of the sensory attributes scores with MD on real rose bushes. It used the 171 videos available for the three natural condition stages. Sensory attribute variables were defined as the average score of the panelists by product and analyzed conjointly with the MD. For assessing the relevance of the MD as predictors, the analysis was based respectively for calibration and validation of the models, on a 2:1 ratio random sampling within all the nine pairwise crossed conditions (stage $\times$ shading).

In a first approach, links between the sensory attribute variables and the MD were first evaluated with the Spearman's correlation coefficient $\left(r_{\mathrm{s}}\right)$ to detect eventual monotonic relationships from the calibration dataset. Then prediction of the sensory attributes variables was tested with simple linear regression through ordinary least squares (OLS), the most common and simple regression method (Næs et al., 2011; Kuhn and Johnson, 2013) using the MD as potential predictors one by one and without any stage- or shading-based parameters. Goodness of fit was evaluated with the traditional coefficient of determination and lack of fit with the root mean square error for the entire calibration data (respectively $R^{2}$ and RMSE), and through 10-10 folds cross-validation (respectively $R_{\mathrm{CV}}^{2}$ and $\mathrm{RMSE}_{\mathrm{CV}}$ ). Coefficient of determination and root mean square error of prediction computed from the validation dataset (respectively $Q^{2}$ and RMSEP) were then used to assess the predictive ability of the models with unknown data. Common transformations (power, root, log, exponential and inverse) and normality supervised power-transformation of Yeo-Johnson were applied to the predictors (Yeo and Johnson, 2000) with the aim to better satisfy required linear modeling assumptions (Kuhn and Johnson, 2013) while exploiting more deeply the data still using a relatively simple modeling approach. This analysis was conducted on the plants from the three pooled stages, only with the features obtained from the complete plant mask over 45 plant facets ( $8^{\circ}$ interval) as previously tested for virtual plants.

Secondly, the potential of the MD obtained from the masks of the flowers and the image number effect for the prediction of the sensory attribute related to flowering were separately analyzed using plant videos at S1 and S3 (no flower detected for S2). For this second step, modeling was conducted with the flowering specific MD computed from 120 images ( $3^{\circ}$ interval, the same used for video edition), then $45,15,3$, and finally only one facet. For the one facet test, thus only one value per image feature extracted was available; the image selected was the largest plant facet as done in related studies (Boumaza et al., 2010; Huché-Thélier et al., 2011; Santagostini et al., 2014).

For the second objective: assessing the macroscopic effects of defoliation on plant before its digitizing, the analysis was conducted with the 54 videos made with the plants which were imaged before and after manual defoliation during the third stage: 27 S3D videos, and the 27 corresponding S3 videos just before defoliation. Effect of the defoliation on plant architecture was assessed for each sensory attribute with average scores of the panelists per plant compared with 


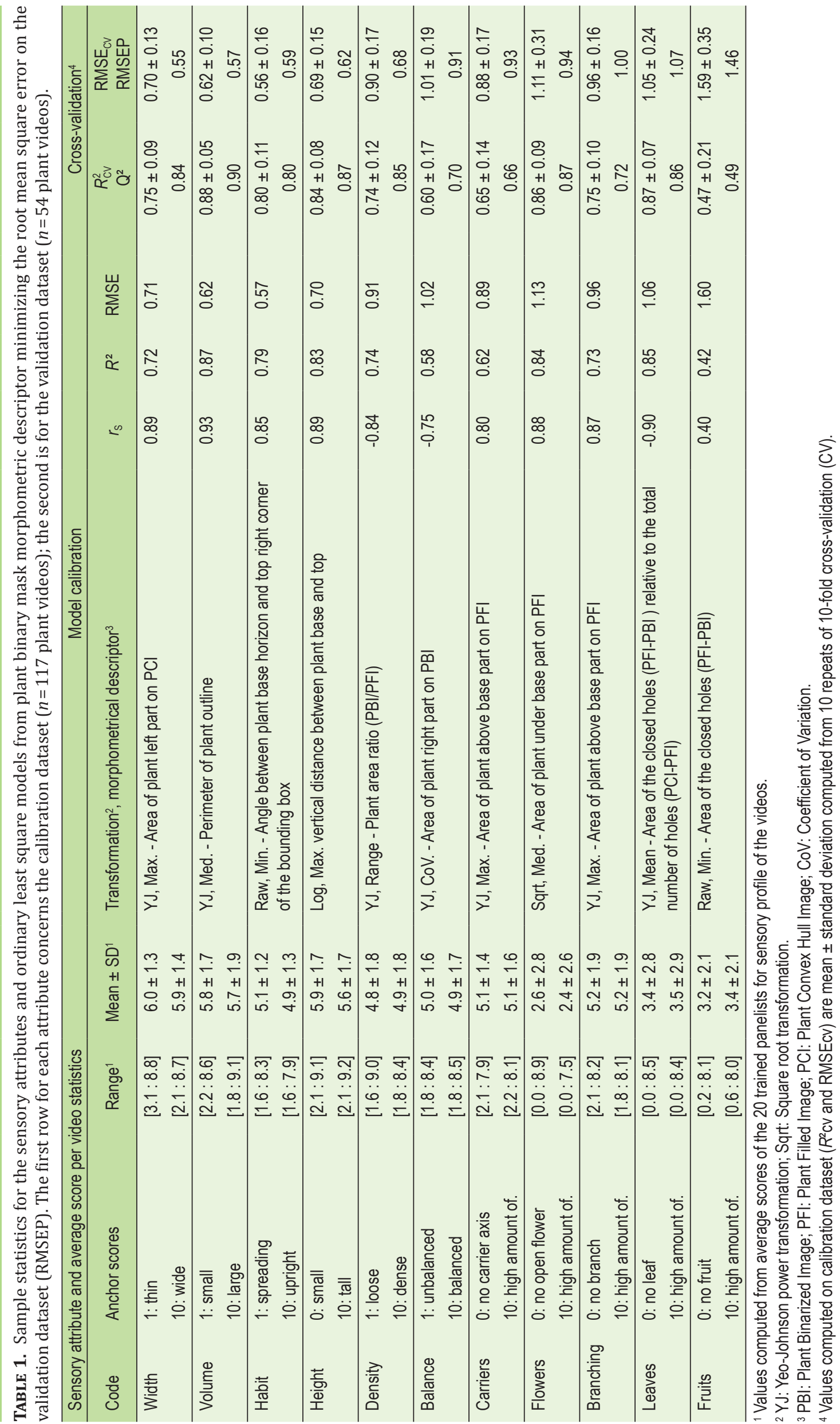


paired data tests. Tests used were performed using the stats package functions using the Student's $t$-test (Welch's adaptation for unequal variances) or the Wilcoxon signed-rank test (with continuity correction in the normal approximation for the $p$-value) if the Shapiro-Wilk test rejected the normality hypothesis with error level $\alpha=0.05$.

\section{Results and discussion}

\section{Predictive modeling}

For each sensory attribute excepted for quantity of 'Fruits', high to very high significant correlations were found with many MD from the plant binary masks $\left(r_{\mathrm{s}}\right.$ ranging from 0.75 to 0.94 in absolute value; Table 1 ). Cross-validations did not highlight specifically overfitted models, however, the models minimizing RMSEP reported were not necessarily based on the most correlated MD. For dimensions (width, volume, and height), habit, density, leaf, flower and branching quantity related attributes, minimizing RMSEP models explained rather quite a large amount of the response variables (both $R^{2}, R_{\mathrm{CV}}^{2}$ and $Q^{2}>0.7$ ).

Nonetheless, all the models except for 'Fruits' presented an acceptable accuracy on calibration and also validation datasets (maximum error indices $<1$ ) especially for 'Volume' with error of $7.8 \%$ (normalized RMSE to response range), while the worst were for carriers and branching (RMSEP = 0.93 and 1.00 respectively) leading to prediction errors of 15.9 and $16.0 \%$. Interestingly, most of the relations reported were not linear, however, few seem tightly specific. For instance, for 'Height', our model was rather consistent with that formerly presented in Garbez et al. (2016), but log transformation better linearized the relation and led to $Q^{2}$ increasing from 0.83 to 0.87 , and NRMSEP decreasing from 10.1 to $8.8 \%$. Also, in general, it was noteworthy that Yeo-Johnson (YJ) normality-supervised power transformation yielded to better results. For the 'Width', mean width of the bounding box $\left(r_{\mathrm{S}}=0.91\right)$ did not outperform the measurement of the YJ area of plant left part on PCI. While plant MD enabled us to report an acceptable model for 'Flowers', similar models were reported for 'Branching' and 'Carriers', closely related by essence, but none was satisfying for the fruits. This was not expected for the flowers, nonetheless this reflects again that the number of flowers is tightly associated with the plant vegetative development level (Garbez et al., 2018). For fruits, no specific image feature was designed since this specific segmentation seems unfeasible with the color information and image analysis methods tested up to now.

Therefore, plant 3D reconstruction does not seem to be particularly needed for instance. However, as demonstrated with the virtual material (Garbez et al., 2016), multivariate models including several MD with feature selection algorithms may be more relevant and accurate (Nœs and Kowalski, 1989; Kuhn and Johnson, 2013; Silva et al., 2013). Nonetheless, image acquisition and processing may strongly benefit from both RGB and depth data sensors as proposed by Chéné et al. (2016). Indeed, coupled with color, depth information represents a valuable way to ease, at least, plant segmentation from the background, the turntable, the pot and the different organs, but also for testing depth-based descriptors giving access to the 3D of the plant facets. Even less important than flowers during growth, fruits are also decorative for numerous ornamental plants. To the best of our knowledge, plant part characterization with 2D image features at the organ-scale is well documented. This is especially true for flowers and leaves of numerous plant species, and for fruits and vegetables for which detection and characterization by remote sensing is also feasible with good accuracy (Gongal et al., 2015; Horgan, 2001; Kawabata et al., 2009; Ruiz-Altisent et al., 2010; Moreda et al., 2012). However within entire ornamental plant products, fruit detection and characterization issues have not been addressed yet. Thus this need, not especially for the fruits but for all the organs at their own scale, represents another challenge to be addressed for non-destructive plant multiscale image-based phenotyping tools (Rousseau et al., 2015).

\section{Number of images}

Unsurprisingly, for 'Flowers' the MD computed from flower masks led to quite better models. Interestingly, whatever the number of images used, it was the same MD which provided the best model with the lower RMSEP (Table 2). Indeed, the "mean of the cumulated area of the pixels assigned to flowers (linearized by square root transformation)" provided models with $R^{2}$ ranging from 0.87 to 0.96 and simi$\operatorname{lar} Q^{2}$. Nonetheless, while model statistics were not much contrasted between the MD computed from 3 to 120 images, results highlighted that prediction for 'Flowers' is quite enhanced with more than only one image. Indeed models obtained with 3, 15, 45 and 120 images all presented a reduced error of prediction by near the half, decreasing RMSEP normalized to the variable response range from $10.4 \%$ to $6.2 \%$. Moreover with the largest facet only, both $R_{\mathrm{CV}}^{2}$ and RM$\mathrm{SE}_{\mathrm{CV}}$ presented the highest standard deviations strengthening that for precision and robustness, more than one image should be considered. As it is also mentioned by Harmsen et al. (2009) for developing multi-target tracking algorithm counting flowers, or for enhancing manual and automated plant grading (Kohsel, 2001; Kohsel and Bennedsen, 2001),

TABLE 2. 'Flower' sensory attribute model performance with square root of "mean of the cumulated area of the pixels assigned to flowers" according to the number of images for videos presenting leafy plants ( $N=114$ plant videos from stage 1 and 3 ).

\begin{tabular}{lccccccccc}
\hline \multirow{2}{*}{ Nr. of images } & \multicolumn{9}{c}{ Calibration with 10-10 cross-validation } \\
\cline { 2 - 10 } & $r_{\mathrm{S}}$ & $R^{2}$ & RMSE & NRMSE $(\%)$ & $R_{\mathrm{CV}}^{2}$ & RMSE $_{\mathrm{CV}}$ & $Q^{2}$ & Ralidation $^{2}$ \\
\hline 1 & 0.92 & 0.87 & 0.92 & 10.28 & $0.89 \pm 0.06$ & $0.91 \pm 0.21$ & 0.88 & 0.86 & 10.35 \\
3 & 0.98 & 0.96 & 0.52 & 5.80 & $0.97 \pm 0.02$ & $0.52 \pm 0.13$ & 0.96 & 0.52 & 6.21 \\
15 & 0.98 & 0.96 & 0.52 & 5.80 & $0.97 \pm 0.02$ & $0.52 \pm 0.13$ & 0.96 & 0.52 & 6.21 \\
45 & 0.98 & 0.96 & 0.51 & 5.75 & $0.97 \pm 0.02$ & $0.51 \pm 0.13$ & 0.96 & 0.52 & 6.23 \\
120 & 0.98 & 0.96 & 0.51 & 5.74 & $0.97 \pm 0.02$ & $0.51 \pm 0.13$ & 0.96 & 0.52 & 6.18 \\
\hline
\end{tabular}

${ }^{1}$ Calibration using $n=78$ plant videos; Spearman correlation $(r S)$, coefficient of determination $\left(R^{2}\right)$, root mean square error (RMSE), normalized RMSE (NRMSE), $R^{2} \mathrm{Cv}$ and RMSEcv values are mean \pm standard deviation computed from 10 repeats of 10 -fold cross-validation (CV).

2 Validation using $n=36$ plant videos. 
TABLE 3. Visual characterization of rose bushes before and after plant defoliation for the sensory attributes not related to leaves. Bold names highlight attributes for which significant differences $(\alpha=0.05)$ were not detected.

\begin{tabular}{lcccc}
\hline Sensory attribute & Before $^{1}$ & After $^{1}$ & Variation $^{2}$ & $P_{\text {-value }}$ \\
\hline Fruits & $2.3 \pm 0.3$ & $4.1 \pm 0.3$ & 2.1 & $5.9 \mathrm{E}-06$ \\
Density & $5.6 \pm 0.4$ & $3.9 \pm 0.3$ & -1.6 & $5.9 \mathrm{E}-06$ \\
Volume & $7.3 \pm 0.2$ & $6.5 \pm 0.2$ & -0.7 & $7.1 \mathrm{E}-12$ \\
Habit & $4.9 \pm 0.2$ & $5.4 \pm 0.2$ & 0.5 & $8.7 \mathrm{E}-06$ \\
Width & $7.3 \pm 0.1$ & $6.8 \pm 0.2$ & -0.5 & $4.5 \mathrm{E}-11$ \\
Balance & $5.4 \pm 0.3$ & $5.8 \pm 0.3$ & 0.4 & $7.2 \mathrm{E}-05$ \\
Branching & $6.3 \pm 0.3$ & $6.0 \pm 0.3$ & -0.4 & $4.6 \mathrm{E}-04$ \\
Carriers & $5.9 \pm 0.2$ & $5.7 \pm 0.3$ & -0.2 & $9.3 \mathrm{E}-03$ \\
Flowers & $5.8 \pm 0.4$ & $5.7 \pm 0.5$ & -0.2 & $2.6 \mathrm{E}-01$ \\
Height & $6.8 \pm 0.2$ & $6.8 \pm 0.2$ & 0.0 & $9.2 \mathrm{E}-01$ \\
\hline
\end{tabular}

${ }^{1}$ Values are mean \pm standard error of $n=27$ plants assessed in rotation on videos made 15 months after cutting through a sensory profile made with 20 trained subjects. Plants used came from three shading conditions (under nets with $55 \%, 75 \%$ of shading, and $0 \%$ as control without shading net).

${ }^{2} P$-values and variations are reported according to paired tests: Student's $t$-test (Welch's adaptation for unequal variances $t$-test); or Wilcoxon (continuity correction method) if the normality assumption was not satisfied (Shapiro-Wilk's test at the 0.05 threshold).

taking into account several facets of the plants is especially recommended. At least, the present study demonstrated it robustly with an image analysis-based model for assessing the flower quantity perception through a sensory profile approach.

\section{Effect of defoliation}

Except for 'Flowers' and 'Height' sensory attributes, plant defoliation implied highly significant perception modifications (Table 3; $p$-values at least under 1\%). Major impact was for the fruits which were more visible without leaves. Scores for density and volume as expected were also reduced. Also, without leaves, the panel perceived the plants as more balanced, maybe since leaves were not regularly distributed within the plants; and as less ramified (carriers and branching), maybe because panelists overestimated the quantity of axes when the plants presented leaves. Nonetheless, most critical impacts were for habit and width. Foliar mass removal reduced the bending of non-othotropic axes and this was effectively perceived by the panel which characterized the defoliated plants as thinner, more erected, but not taller. Thus, for studies related to plant shape and growth habit, defoliation before architecture digitizing, whatever the methods used, should not be recommended. However, plant architecture models presented in Garbez et al. (2018) included for S3 plants the measurements obtained on defoliated plants stored in cold chamber up to two months. Therefore, in such studies, it is at least recommended to collect leaf data characteristics during or in parallel of stem digitizing, thus enabling deeper analysis including visual, metric, and mass leaf characteristics within plant virtual models as recently addressed for the rose bush (Gao et al., 2012; Demotes-Mainard et al., 2013).

\section{Conclusion and perspectives}

The results obtained confirm the possibility of an objective and automated method to characterize 3D visual appearance of real rose bush. Even with real plants presenting rather larger phenotypic diversity, image analysis of several plant facets to compute the morphometrical descriptors proposed by Garbez et al. (2016) is an efficient way to establish rather good to acceptable predictive models for most of the visual traits considered. The possible reduction in the num- ber of images makes the method easier and opens up wider areas of application. The various states of the plants throughout their development can be integrated implicitly and first investigations for the flower quantity perception modeling stressed that a limited number of images, here 3 , each interspaced by $120^{\circ}$, provided consistent results with those obtained from the processing of larger image sequences. The good results obtained with or without leaves also open possibilities to study the relations between the morphometric descriptors and the architectural processes (Barthélémy and Caraglio, 2007). Thus, such automation possibility represents an interesting approach for assessing ornamental plant visual appearance in relation to architecture plasticity and the growing conditions. It allows to integrate on the one hand the analysis of the plant from 2D to 3D with for the sensory attribute 'Flowers', with a similar Spearman's correlation coefficient $\left(2 \mathrm{D} r_{\mathrm{S}}=0.82 ; 3 \mathrm{D} r_{\mathrm{S}}=0.88\right.$ ) (Santagostini et al., 2014). On the other hand, it makes it possible to calculate the correlation coefficient of 9 other criteria with an $r_{\mathrm{s}}$ value larger than 0.75 .

However, for the sake of precision, multivariate models may be necessary to obtain better predictive models. In contrast for both predictive and explicative modeling purposes, expert knowledge, feature selection algorithms as other regression methods assuming either linear and non-linear modeling with large predictor numbers is thus recommended for selecting the most explicative and relevant features in relation to the plant material studied, experimental conditions and objectives.

Finally, as hypothesized along related previous studies (Garbez et al., 2015, 2016), merging instrumental methods related to sensory analysis evaluation and virtual plant models implemented from architectural data, including leaf visual and physic characteristics, may thus result into a powerful integrated methodology to study consumer preferences of today and tomorrow with an innovative and scientific visual quality management approach. Like fresh horticultural products, especially fruits and vegetables, the evolution of sensory sciences can evolve the knowledge and the practice to favor a good concordance between visual quality and consumers preferences (Kohsel and Bennedsen, 2001; Meilgaard et al., 2006). 


\section{Acknowledgments}

The authors thank the Pays de la Loire Regional Council for their financial support; as the Pépinières Desmartis nursery and the National Association for Research and Technology (ANRT) for the Industrial Agreements for Research Training grant awarded (CIFRE grant number 2013/0410). The authors thank all the people who took part in the sensory experiments, as Rémi Gardet and his team (INEM) from the Agrocampus Ouest experimental station for the crop monitoring support.

\section{Declarations of interest}

No interests declared.

\section{References}

Barthélémy, D., and Caraglio, Y. (2007). Plant architecture: A dynamic, multilevel and comprehensive approach to plant form, structure and ontogeny. Ann. Bot. 99(3), 375-407. https://doi.org/10.1093/aob/ mcl260.

Boumaza, R., Demotes-Mainard, S., Huché-Thélier, L., and Guérin, V. (2009).Visual characterization of the esthetic quality of the rosebush. J. Sensory Studies 24(5), 774-796. https://doi.org/10.1111/j.1745459X.2009.00238.x.

Boumaza, R., Huché-Thélier, L., Demotes-Mainard, S., Le Coz, E.L., Leduc, N., Pelleschi-Travier, S., Qannari, E.M., and Guérin, V. (2010). Sensory profiles and preference analysis in ornamental horticulture: The case of the rosebush. Food Qual. and Pref. 21(8), 987-997. https://doi.org/10.1016/j.foodqual.2010.05.003.

Chéné, Y., Rousseau, D., Belin, É., Garbez, M., Galopin, G., and Chapeau-Blondeau, F. (2016). Shape descriptors to characterize the shoot of entire plant from multiple side views of a motorized depth sensor. Machine Vision and Applic. 27(4), 447-461. https://doi. org/10.1007/s00138-016-0762-x.

Demotes-Mainard, S., Bertheloot, J., Boumaza, R., Huché-Thélier, L., Guéritaine, G., Guérin, V., and Andrieu, B. (2013). Rose bush leaf and internode expansion dynamics: Analysis and development of a model capturing interplant variability. Front. Plant Sci. 4(418) https://doi.org/10.3389/fpls.2013.00418.

Gao, M., Van der Heijden, G., Vos, J., Eveleens, B.A., and Marcelis, L.F.M. (2012). Estimation of leaf area for large scale phenotyping and modeling of rose genotypes. Sci. Hortic. 138, 227-234. https://doi. org/10.1016/j.scienta.2012.02.014.

Garbez, M., Galopin, G., Sigogne, M., Favre, P., Demotes-Mainard, S., and Symoneaux, R. (2015). Assessing the visual aspect of rotating virtual rose bushes by a labeled sorting task. Food Qual. and Pref. 40, 287-295. https://doi.org/10.1016/j.foodqual.2014.06.008.

Garbez, M., Chéné, Y., Belin, É., Sigogne, M., Labatte, J.M., Hunault, G., and Galopin, G. (2016). Predicting sensorial attribute scores of ornamental plants assessed in 3D through rotation on video by image analysis: A study on the morphology of virtual rose bushes. Comp. and Electr. in Agricult. 121, 331-346. https://doi.org/10.1016/j. compag.2016.01.001.

Garbez, M., Symoneaux, R., Belin, É., Caraglio, Y., Chéné, Y., Donès, N., Durant, J.B., Hunault, G., Relion, D., Sigogne, M., Rousseau, D., and Galopin, G. (2018). Ornamental plants architectural characteristics in relation to visual sensory attributes: A new approach on the rose bush for objective evaluation of the visual quality. Eur. J. Hortic. Sci. 83(3), 187-201. https://doi.org/10.17660/eJHS.2018/83.3.8.

Godin, C. (2000). Representing and encoding plant architecture: A review. Ann. of Forest Sci. 57(5), 413-438. https://doi.org/ 10.1051/forest:2000132

Gongal, A., Amatya, S., Karkee, M., Zhang, Q., and Lewis, K. (2015). Sensors and systems for fruit detection and localization: A review.
Comp. and Electr. in Agricult. 116, 8-19. https://doi.org/10.1016/j. compag.2015.05.021.

Harmsen, S.R., and Koenderink, N.J.J.P. (2009). Multi-target tracking for flower counting using adaptive motion models. Comp. and Electr. in Agricult. 65(1), 7-18. https://doi.org/10.1016/j. compag.2008.07.004.

Horgan, G.W. (2001). The statistical analysis of plant part appearance - A review. Comp. and Electr. in Agricult. 31(2), 169-190. https:// doi.org/10.1016/S0168-1699(00)00190-3.

Huché-Thélier, L., Boumaza, R., Demotes-Mainard, S., Canet, A., Symoneaux, R., Douillet, O., and Guérin, V. (2011). Nitrogen deficiency increases basal branching and modifies visual quality of the rose bushes. Sci. Hortic. 130(1), 325-334. https://doi.org/10.1016/j. scienta.2011.07.007.

Kawabata, S., Yokoo, M., and Nii, K. (2009). Quantitative analysis of corolla shapes and petal contours in single-flower cultivars of lisianthus. Sci. Hortic. 121(2), 206-212. https://doi.org/10.1016/j. scienta.2009.01.024.

Kohsel, L. (2001). New unsupervised approach for solving classification problems with computer vision. Acta Hortic. 562, 361375. https://doi.org/10.17660/ActaHortic.2001.562.43.

Kohsel, L., and Bennedsen, B.S. (2001). Performance of human experts grading pot roses in a commercial environment. Acta Hortic. 562, 273-283. https://doi.org/10.17660/ActaHortic.2001.562.32.

Kuhn, M. (2008). Building predictive models in $\mathrm{R}$ using the caret package. J. Statistical Softw. 28(5). https://doi.org/10.18637/jss. v028.i05.

Kuhn, M. (2016). caret: Classification and Regression Training (Version 6.0-68). http://cran.r-project.org/package=caret.

Kuhn, M., and Johnson, K. (2013). Applied Predictive Modeling (New York, USA: Springer). https://doi.org/10.1007/978-1-4614-6849-3.

Li-Marchetti, C., Le Bras, C., Relion, D., Citerne, S., Huché-Thélier, L., Sakr, S., and Crespel, L. (2015). Genotypic differences in architectural and physiological responses to water restriction in Rose bush. Front. Plant Sci. 6(355). https://doi.org/10.3389/fpls.2015.00355.

Meilgaard, M.C., Carr, B.T., and Civille, G.V. (2006). Sensory Evaluation Techniques, $4^{\text {th }}$ edn. (Boca Raton: CRC Press). https:// doi.org/10.1201/b16452.

Moreda, G.P., Muñoz, M.A., Ruiz-Altisent, M., and Perdigones, A. (2012). Shape determination of horticultural produce using twodimensional computer vision - A review. J. Food Engin. 108(2), 245261. https://doi.org/10.1016/j.jfoodeng.2011.08.011.

Næs, T., Brockhoff, P., and Tomic, O. (2011). Statistics for Sensory and Consumer Science (Chichester: John Wiley \& Sons). https://doi. org/10.1002/9780470669181.

Nœs, T., and Kowalski, B. (1989). Predicting sensory profiles from external instrumental measurements. Food Qual. and Pref. 1(4-5), 135-147. https://doi.org/10.1016/0950-3293(89)90001-3.

Otsu, N. (1979). A threshold selection method from gray level histogram. IEEE Transactions on Systems, Man and Cybernetics 9, 62-66. https://doi.org/10.1109/TSMC.1979.4310076.

R Development Core Team. (2015). R: A language and environment for statistical computing (V. 3.2.3). (Vienna, Austria: R Foundation for Statistical Computing). http://www.R-project.org/.

Rousseau, D., Chéné, Y., Belin, E., Semaan, G., Trigui, G., Boudehri, K., and Chapeau-Blondeau, F. (2015). Multiscale imaging of plants: current approaches and challenges. Plant Methods 11(1), 6. https:// doi.org/10.1186/s13007-015-0050-1. 
Ruiz-Altisent, M., Ruiz-Garcia, L., Moreda, G.P., Lu, R., HernandezSanchez, N., Correa, E.C., and García-Ramos, J. (2010). Sensors for product characterization and quality of specialty crops. Comp. and Electr. in Agricult. 74(2), 176-194. https://doi.org/10.1016/j compag.2010.07.002.

Santagostini, P., Demotes-Mainard, S., Huché-Thélier, L., Leduc, N., Bertheloot, J., Guérin, V., and Boumaza, R. (2014). Assessment of the visual quality of ornamental plants: Comparison of three methodologies in the case of the rosebush. Sci. Hortic. 168, 17-26. https://doi.org/10.1016/j.scienta.2014.01.011.

Silva, L., Koga, M.L., Cugnasca, C.E., and Costa, A.H.R. (2013). Comparative assessment of feature selection and classification techniques for visual inspection of pot plant seedlings. Comp. and Electr. in Agricult. 97, 47-55. https://doi.org/10.1016/j. compag.2013.07.001.

Yeo, I.K., and Johnson, R.A. (2000). A new family of power transformations to improve normality or symmetry. Biometrika 87(4), 954-959. https://doi.org/10.1093/biomet/87.4.954.

Received: Jan. 25, 2019

Accepted: Jul. 22, 2019

Addresses of authors:

M. Garbez ${ }^{1,2}$, É. Belin ${ }^{3}$, Y. Chéné ${ }^{3}$, N. Donès ${ }^{4}$, G. Hunault ${ }^{5}$,

D. Relion ${ }^{1}$, M. Sigogne ${ }^{1}$, R. Symoneaux ${ }^{6}$, D. Rousseau ${ }^{7}$ and

G. Galopin ${ }^{1, *}$

${ }^{1}$ IRHS, INRAE, Institut Agro, Université d'Angers, SFR 4207

QuaSaV, 49071, Beaucouzé, France

2 Pépinières Desmartis, Bergerac, France

${ }^{3}$ Université d'Angers, Laboratoire Angevin de Recherche en Ingénierie des Systèmes (LARIS), Angers, France

${ }^{4}$ PIAF, INRAE, UCA, Clermont-Ferrand, France

${ }^{5}$ Université d'Angers, Laboratoire Hémodynamique, Interaction, Fibrose, et Invasivité Tumorale Hépatique (HIFIH), Angers, France

${ }^{6}$ Unité de Recherche GRAPPE, Université Bretagne Loire, Ecole Supérieure d'Agricultures (ESA), INRA, Angers, France

${ }^{7}$ Université de Lyon, Centre de Recherche en Acquisition et Traitement de l'Image pour la Santé (CREATIS),

Villeurbanne, France

* Corresponding author;

E-mail: gilles.galopin@agrocampus-ouest.fr

Tel.: (+33)-241-225-430

Postal address: Agrocampus Ouest, 2 rue Le Nôtre, 49045 Angers Cedex 01, France 